\author{
Julia DIEDEREN, ${ }^{1}$ Harry GRUPPEN, ${ }^{1}$ Rob HARTOG, ${ }^{2}$ \\ Gerard MOERLAND, ${ }^{2}$ and Alphons G. J. VORAGEN ${ }^{1}$ \\ ${ }^{1}$ Wageningen University, Laboratory of Food Chemistry \\ ${ }^{2}$ Wageningen University, School of Technology and Nutrition
}

\title{
DESIGN OF ACTIVATING DIGITAL LEARNING MATERIAL FOR FOOD CHEMISTRY EDUCATION
}

\author{
Received 18 June 2003; in final form/accepted 12 September 2003
}

\begin{abstract}
A complete set of digital exercises for introductory Food Chemistry has been developed. The major function of the exercises is to promote active acquisition of food chemistry knowledge. This paper describes the design process and the result of the design process. Design guidelines and requirements were derived, based on theories about cognitive load, motivation and active learning. The digital exercises were designed according to these guidelines. Next, teachers, students, and experts in (food) chemistry, education and user-interface design tested the digital exercises against the design requirements. Consequentially, a number of exercises were adjusted and currently the exercises are in use at several universities. The article describes the exercises in detail, with several illustrative examples. An in depth view on the possibilities to create digital learning objects for food chemistry in accordance to a set of practical guidelines is given. [Chem. Educ. Res. Pract:: 2003, 4, 353-371]
\end{abstract}

KEY-WORDS: food chemistry; design process; digital exercises; formative evaluation; design guidelines; motivation; active learning; cognitive load theory

\section{INTRODUCTION}

\section{The course food chemistry}

At Wageningen University the course Food Chemistry is an introductory BSc level course of the Food Technology curriculum. In this course students should acquire basic knowledge on food chemistry and develop a set of laboratory skills. The main learning goals of this course are:

The student who has successfully completed the course should:

- demonstrate qualitative knowledge about chemical and biochemical reactions in food;

- be able to explain the occurrence of reactions by looking at the structure of the compounds;

- demonstrate insight in the influence of the environment and process conditions on the occurrence of (bio) chemical, physical chemical and enzymatic reactions;

- be able to calculate the effect of extrinsic factors on the reactions on food compounds occurring during processing and storage;

- be able to choose analytical methods to analyse food compounds;

- be able to demonstrate experimental skills on chemical analysis of foods. 
The course includes a multitude of different facts and concepts in great detail. Most students feel initially overwhelmed, intrinsic motivation of the students is low and the course lacks learning material that invites active learning. These are probably the reasons why the acquisition of the knowledge and concepts by students is low: the student's ambition is limited to "being able to pass the exam". Although students indicate during further education that the course is useful for the food science curriculum, over the years teachers in follow up courses report low retention of the knowledge that should have been acquired in the introductory course.

\section{Digital exercises}

Earlier (Diederen, 2002) different kinds of digital learning materials have been distinguished for the food chemistry course: cases, presentational learning objects and digital exercises. The present paper is focussing on the digital exercises. Digital exercises are interactive questions that invite students to practice on all kinds of topics within food chemistry. The digital exercises are designed mainly to facilitate the acquisition and use of domain specific knowledge.

There are several reasons why specifically digital exercises are developed. Exercises give the opportunity for the students to learn by being active, to test their knowledge, or to prepare for examination. Exercises can be used in several ways, e.g. as self-study, in the lectures, and during working classes. Exercises can support active learning of concepts over a wide range and the number of possible types of exercises allows for sufficient variation. Earlier, lectures were used to articulate the details of several food chemistry concepts to the students. Exercises can take over this part, so there is more time in lectures to dedicate to the social context of food chemistry. Also, the opportunities of digital learning material are several: colourful visuals can be produced at low costs, there are many possibilities to activate the student and to give immediate feedback to various students at the same time, the maintenance cycle can be short, and distribution is easy.

\section{The design process}

According to Weston and co-writers (Weston, 1999) the design of digital learning material should follow general guidelines that come from instructional design (learning and instruction), subject matter (content issues, learning goals), language (semantic and syntactic issues), presentation (user interface design) and computer technical issues (information and communication technology, ICT). This article will highlight those design guidelines that have played a major role in the design process for the food chemistry digital exercises. The design process is visualised in Figure 1. In the first stage of this process, design guidelines and requirements were drafted from learning and instruction, (food chemistry) subject matter and learning goals, and user interface design. Guidelines direct the process of design: they can be used as a compass heading that gives direction along the way to the final

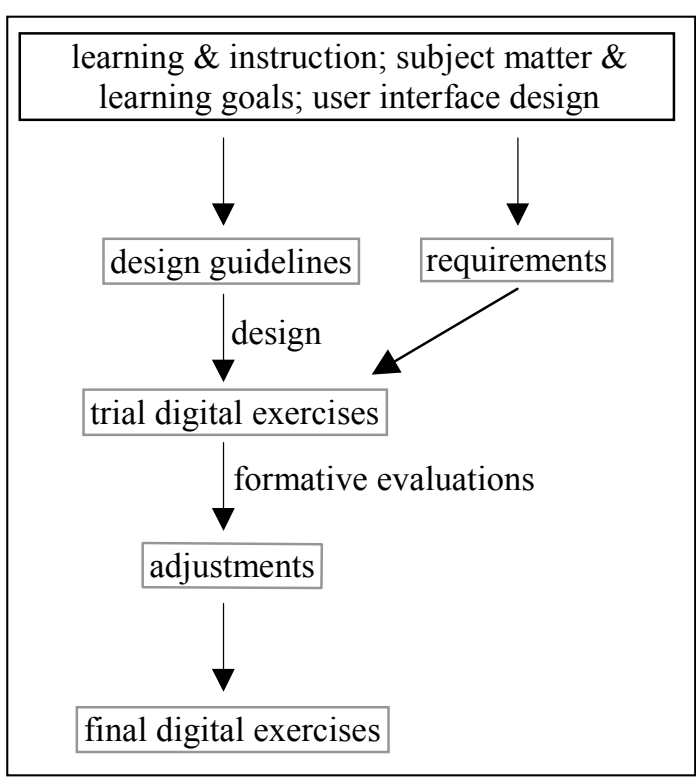

FIGURE 1: The design process of digital learning material. 
design. Requirements are demands that the final design should meet. The second stage resulted in trial digital exercises. The third stage of the design process consisted of the exposure of the trial exercises to various formative evaluations. In these formative evaluations experts and students tested whether the exercises satisfy the requirements. These evaluations resulted in adjustments to the trial exercises and led to the final digital exercises.

This article lists the design guidelines and requirements, followed by a description and discussion of the formative evaluations and the proposed adjustments. Finally, a description of the final digital exercises is given in detail.

\section{DESIGN GUIDELINES}

\section{Design guidelines based on learning and instruction}

The knowledge, insights and skills that students acquire during the course Food Chemistry are considered necessary as a basis to successfully complete problem oriented education in the curriculum Food Science, to understand and solve problems during (future) work, and as a starting point for further education including life long learning. The laboratory of Food Chemistry of Wageningen University supports the opinion that a successful academic researcher should have an extensive body of domain specific knowledge (Owen, 1989). Indeed, students often face difficulties with problem solving because of lack of knowledge next to information overload, experience, confidence and the mental flexibility to observe new ideas (Johnstone, 2001). The main purpose of the digital exercises is to facilitate the construction of the large body of detailed knowledge that is considered essential in food chemistry.

Given this main purpose and the characteristics of the subject matter, for the design of the digital exercises practical guidelines were derived from three perspectives on learning and instruction: 1. cognitive load, 2. motivation of students, and 3. active learning.

\section{Cognitive Load Theory}

In cognitive psychology, working memory refers to a limited capacity system allowing the temporary storage and manipulation of information necessary for complex tasks such as comprehension, learning and reasoning (Baddeley, 1992, 2000). Cognitive load (CL) refers to the total amount of mental activity imposed on working memory at an instance in time. The Cognitive Load Theory (CLT) (Sweller, 1998; Kirschner, 2002) assumes a limited capacity of working memory and a very large long term memory that holds schemata. CL (or working memory load) may be affected by the instrinsic nature of the material, by the manner in which the material is presented and the activities required from students (Sweller, 1998; Bannert, 2002; Kirschner, 2002). CL induced by the manner in which the material is presented can be reduced by a good design of the learning material, in particular CL induced by the intrinsic nature of the learning material can be reduced by adequate sequencing the information (Bannert, 2002). CL induced by activities required of students that are relevant to construction of schemata should be increased and CL induced by activities that are irrelevant to construction of schemata should be minimised (Sweller, 1988, 1998).

Especially for a course as food chemistry, in which many dissimilar facts are related (the intrinsic nature of the material), it is very important to make sure that adequate levels of $\mathrm{CL}$ are imposed. To impose adequate levels of CL guidelines g1 to g6 in Table 1 were formulated for the design of the digital exercises. Important aspects of these guidelines are prior knowledge, adequate sequencing of information, just-in-time presentation of information and visualisation. 


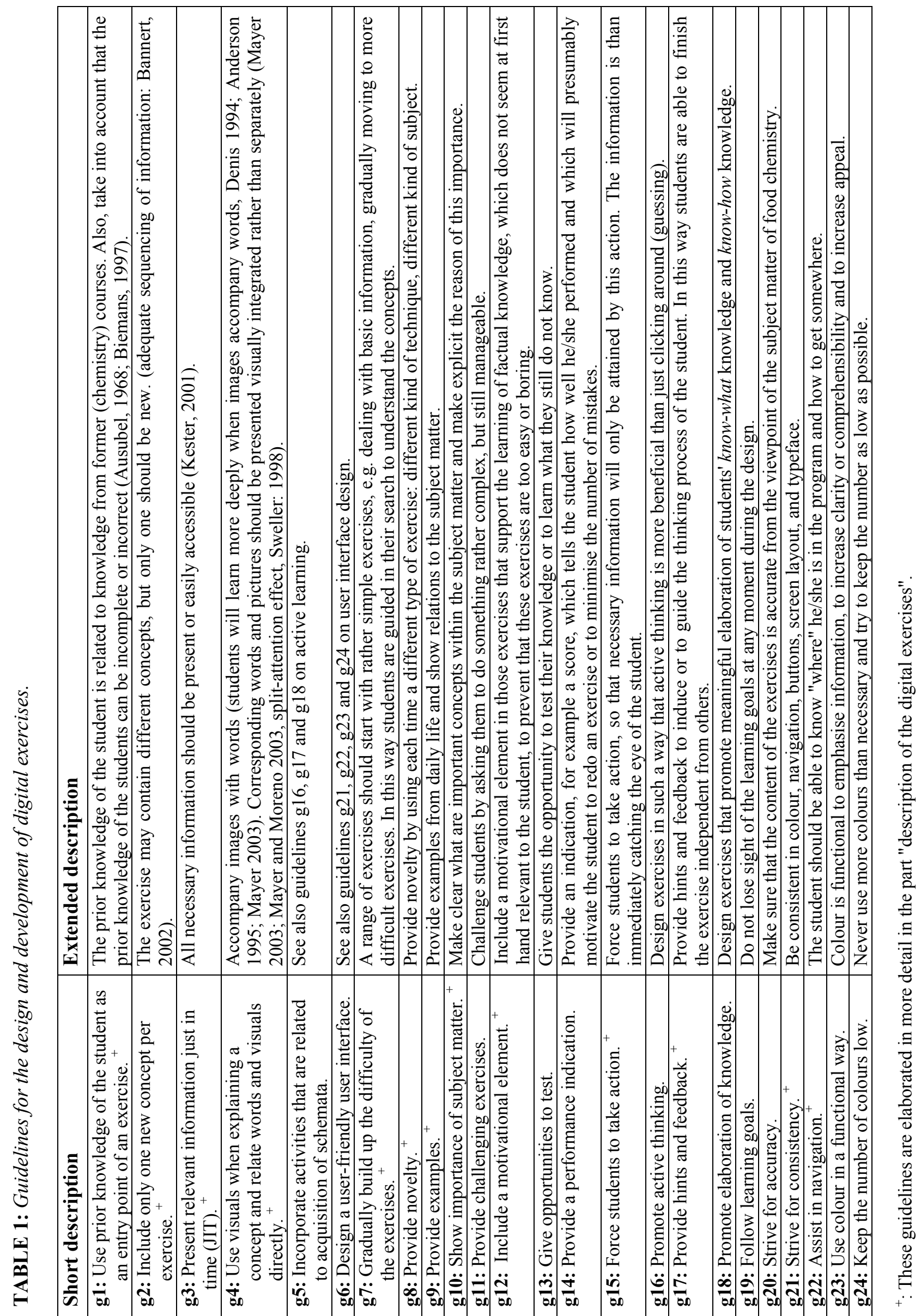




\section{Motivation of students}

Motivation is essential to learning: the extent of learning achieved can be modulated by the strength of the drive and its underlying motivation (Hull's drive reduction theory: Hull, 1940). Keller (1983) established a model on motivation of students: the ARCS model. This model identifies four essential components for motivating instruction. The four components are Attention (arouse and sustain curiosity and interest), Relevance (make a connection to students' needs, interests, and motives), Confidence (help students develop a positive expectation for successful achievement) and Satisfaction (provide extrinsic and intrinsic reinforcement for effort).

For the design of motivational exercises the design guidelines g2 and g7 to g14 in Table 1 were derived from the ARCS model. Guidelines $\mathrm{g} 8$ and $\mathrm{g} 12$ are related to attention. Guidelines g9 and g10 are related to relevance. Guidelines g2, g7 and g11 are related to confidence. And finally, guidelines g11, g13 and g14 are related to satisfaction.

\section{Active learning}

Several authors assert that active learning is a necessity for understanding, acquiring knowledge and retention of this knowledge (Anderson, 1995; Merriënboer, 1997; Keyser, 2000). By active learning students are actively working with (prior) knowledge and information that is presented during the activities. In this way knowledge can be integrated into existing schemata or new schemata can be constructed on the particular topics of each exercise. These schemata are important for being able to work efficient on similar topics in research, future work and future learning (Owen, 1989).

Exercises demand students to act and are, therefore, by definition activating. Whether this activation is effective in facilitating knowledge and schema acquisition by students depends on what students need to do in the exercises and the way the exercises are built. Design guidelines g15 to g18 in Table 1 were used to develop effective activating digital exercises.

When looking at the guidelines $\mathrm{g} 1$ to $\mathrm{g} 18$, it becomes clear that some guidelines can be based on both CLT as well as on theories about motivation and active learning. For example, if students are motivated to do something, an active behaviour will be induced, or if cognitive overload occurs, students will get frustrated and motivation will drop.

\section{Design guidelines based on Food Chemistry subject matter and learning goals}

There are two important guidelines that the learning material should follow from the point of view of food chemistry: g19, which deals with learning goals and g20, which deals with the accurate content of the exercises (see Table 1).

It seems natural that these guidelines are important, but still it is essential for the success of learning material to constantly control during the design process whether for instance the subject matter is accurately presented. Our experience shows that while designing learning material all attention tends to be directed to good educational practices and nice examples, and consequentially less attention is directed to accuracy. Subtle errors are introduced quite easily in this way.

\section{Design guidelines based on user interface design}

User interface design is the discipline that holds theories about designing computer interfaces. Guidelines that are described by Marcus (1997) about Graphical User Interfaces 
(GUI) are followed during the design of the digital learning material. Guidelines mentioned in Table 1 are g21 about consistency, g22 about navigation, and g23 and g24 about colour.

\section{DESIGN REQUIREMENTS}

Table 2 lists the set of design requirements for the digital exercises, the source of each requirement and how this requirement is evaluated.

The design requirements and design guidelines are derived from the same sources. The requirements are used by the evaluators. The designer used the guidelines as well as the requirements to direct the design process.

\section{SHORT DESCRIPTION OF THE TRIAL DIGITAL EXERCISES}

For each subject of the food chemistry course (proteins, saccharides, lipids, phenolic components, and enzymes) trial digital exercises are designed according to the above listed design guidelines. These trial exercises are grouped in sequences of at most 10 numbered exercises. There is a score incorporated within the exercises. For each exercise 10 credit points can be obtained. The sequence of exercises is concluded with a score overview, which shows the students the score of each exercise and the total score for the sequence. To re-do an exercise in the middle of a sequence of exercises, one has to start a sequence from the beginning. Exercises provide hints and feedback and differ greatly in difficulty and type.

The trial exercises were subjected to formative evaluations with respect to different sets of design requirements.

\section{FORMATIVE EVALUATIONS OF THE TRIAL DIGITAL EXERCISES}

The trial exercises have been subjected to formative evaluations, as was shown in the design process (Figure 1), in order to find out whether the exercises met the requirements. The following four formative evaluations have been carried out: (1) an evaluation by expert teachers on the subject, (2) an evaluation by MSc students, (3) an evaluation by a user interface designer, and (4) an evaluation by experts in (food) chemistry and education. The formative evaluations are discussed in this chapter in their chronological order. Every next evaluation was carried out with learning material that was improved according to the previous evaluation. The order of the evaluations 2,3 , and 4 was mainly determined by practical constraints.

\section{Evaluation by subject expert teachers}

For each subject (proteins, saccharides, lipids, phenolic components, enzymes) two requirements (r17 and r18) were tested with a teacher, who is expert on the content of that specific subject. By processing the comments of the five expert teachers into the learning material, the content became accurate, relevant and it was related to the learning goals.

\section{Evaluation by master students}

Four MSc students, who had just finished or were about to finish their MSc degree in Food Science, evaluated the learning material for the requirements $r 1, r 2$ and $r 3$. They had followed the introductory course on food chemistry several years ago, and they had not followed any chemistry courses after this introductory course. This means that their 
TABLE 2: Requirements for the design, development and evaluation of digital exercises.

\begin{tabular}{|c|c|c|}
\hline Requirement & Source & Evaluation \\
\hline $\begin{array}{l}\text { r1: The exercises are clear. (It is clear what needs to be done and the content is } \\
\text { clear.) }\end{array}$ & LI (clt, mot) & $\begin{array}{l}\text { MSc-students } \\
+ \text { case study }\end{array}$ \\
\hline r2: The exercises are manageable. (The student is able to solve the exercise.) & LI (mot) & $\begin{array}{l}\text { MSc-students } \\
+ \text { case study }\end{array}$ \\
\hline r3: Students see the digital exercises as a valuable addition to the readers. & LI & $\begin{array}{l}\text { MSc-students } \\
+ \text { case study }\end{array}$ \\
\hline r4: The exercises are used by students on their own initiative. & LI (mot, act) & case study \\
\hline r5: The exercises are fun to work on. & LI (mot) & case study \\
\hline r6: The content of an exercise is understood after completing the exercise. & LI (mot) & case study \\
\hline r7: Students are able to recognise the exercises in sections of the readers. & LI (mot) & case study \\
\hline $\begin{array}{l}\text { r8: Sections of the readers are according to students easy to remember after } \\
\text { completing the exercises. }\end{array}$ & LI (clt, mot) & case study \\
\hline $\begin{array}{l}\text { r9: Sections of the readers are according to students easy to understand after } \\
\text { completing the exercises. }\end{array}$ & LI (clt, mot) & case study \\
\hline r10: Students are motivated not to guess too much. & LI (mot) & case study \\
\hline $\begin{array}{l}\text { r11: Students are motivated to redo an exercise when the performance for that } \\
\text { exercise was low. }\end{array}$ & LI (mot, act) & case study \\
\hline $\begin{array}{l}\text { r12: The exercises fulfil a need of those students who like to learn in an active and } \\
\text { visual way. }\end{array}$ & LI (mot) & case study \\
\hline r13: Students feel they learned much from doing the exercises. & LI (mot) & case study \\
\hline $\begin{array}{l}\text { r14: Students feel that the exercises contributed to the capability to successfully } \\
\text { pass the final exam. }\end{array}$ & LI (mot) & case study \\
\hline $\begin{array}{l}\text { r15: Experts in pedagogical content knowledge observe the digital exercises as a } \\
\text { valuable addition to the readers. }\end{array}$ & $\overline{\mathrm{LI}}$ & $\begin{array}{l}\text { experts chem } \\
+ \text { edu }\end{array}$ \\
\hline $\begin{array}{l}\text { r16: Experts in the field of learning and instruction confirm that broadly accepted } \\
\text { views in their field have been applied correctly in the digital exercises. }\end{array}$ & LI & $\begin{array}{l}\text { experts chem } \\
+ \text { edu }\end{array}$ \\
\hline r17: The teachers confirm that the content of the exercises is accurate and relevant. & SL & teachers \\
\hline $\begin{array}{l}\text { r18: Teachers confirm that the learning material supports the achievement of the } \\
\text { learning goals. }\end{array}$ & SL & teachers \\
\hline $\begin{array}{l}\text { r19: Experts in (food) chemistry confirm that the exercises apply accepted scientific } \\
\text { views on (food) chemistry in a justified manner. }\end{array}$ & SL & $\begin{array}{l}\text { experts chem } \\
+ \text { edu }\end{array}$ \\
\hline $\begin{array}{l}\text { r20: At least one user-interface expert confirms that generally accepted views on } \\
\text { user interface design are applied in a justified manner. }\end{array}$ & UID & expert UID \\
\hline $\begin{array}{l}\text { r21: At least one user-interface expert confirms that visualisation is realised in a } \\
\text { justified manner. }\end{array}$ & UID & expert UID \\
\hline
\end{tabular}

LI: Learning and Instruction (clt: cognitive load theory, mot: motivation of students, act: activation of students), SL: (Food Chemistry) Subject matter and Learning goals, UID: User Interface Design, chem: chemistry, edu: education. Case study: these requirements were and will be tested in a series of case studies with students in regular settings at different universities.

knowledge of (food) chemistry was insubstantial and probably only slightly higher than the prior knowledge of our target group of students (BSc). The advantages of an evaluation with these master students were several:

- Because of slightly higher prior knowledge, the cognitive load induced by the exercises was lower than for BSc students. Thus, the effort of solving the exercises did not prevent them to direct sufficient attention to evaluate the exercises.

- During their study these students had gained experience with several kinds of learning material and were, therefore, probably more critical than BSc students.

- They were not afraid to criticise, since they will never deal with any of our teachers anymore. 
The general opinions of the students about the learning material were as follows: they liked to do the exercises, most exercises were manageable, and they certainly perceived the surplus value. It was judged frustrating that there is no possibility to navigate between the exercises, to re-do an exercise or skip an exercise within one sequence.

Explanation of difficult words, changes in the lay-out, corrections of semantic errors in the script of the computer-program, more hints or more specific hints, were the few improvements that were made after the sessions with the students. The possibility to navigate through the exercises within one sequence was not incorporated yet. This was first verified with the expert on user interface design.

\section{Evaluation by an expert user interface designer}

The expert in user interface design (M.Sc. in industrial design) had several years experience as a user interface designer in many different (research) projects and designed several websites and computer applications. He evaluated the trial exercises for the requirements $\mathrm{r} 20$ and $\mathrm{r} 21$.

This expert confirmed that screen space has been used optimally and that the use of colours, symbols and layout in the concept exercises were sufficiently consistent. On his advice, navigation functionality was added to each sequence in the form of a link to each exercise from any place within a sequence. Furthermore, on his advice, the design of some buttons was changed to clarify the purpose of these buttons.

\section{Evaluation by experts in chemistry and education}

During a four-hour session, five experts on respectively education (one with and one without chemical background), content pedagogy, food chemistry, and chemistry from several universities (University of Twente, University of Utrecht, and Wageningen University) were invited to look at five different exercises. The requirements r15, r16 and r19 were tested in this session.

The experts took their job seriously and were therefore critical. The overall judgement of the learning material was positive. Visualisation and the possibility of working actively with the information were both regarded as surplus value for education. In general the content was correct. The experts in education looked at the exercises from a perspective different from that of the experts in chemistry. One expert in education declined to give an explicit judgement for the exercises apart from a well defined educational setting. Criticism focussed mainly on insufficient or unsatisfactory feedback. According to all experts, except for the expert in food chemistry, three of the five exercises provided insufficient feedback or feedback that was not specific enough.

The digital exercises were designed for regular students as a complement to existing learning material as readers, books and lecture notes. During the evaluation no books or lecture notes were available to the experts. However, during the evaluation session it became obvious that some experts really needed the lecture notes or an alternative source of background information for the exercises. This explains to a certain extent the opinion of some experts that adequate feedback is missing. Still, the experts' criticism on feedback could be an indication that some exercises needed adjustments for feedback.

Besides some minor corrections in content, no changes were made to the learning material. Instead of enhancing and extending the feedback, we are working on providing more information on-line by implementing parts of the readers and developing more presentational learning objects. This will result in a body of learning material that will be completely self sustained. A case study is necessary to see whether feedback should be 
adjusted. It is too early to say whether the two requirements $\mathrm{r} 15$ and $\mathrm{r} 16$ are met. This requires a more thorough evaluation with experts on learning and instruction.

\section{CONCLUSIONS FROM THE DESIGN PROCESS}

During the design and development the design guidelines were a good help to design learning material that is motivating, activating and that reduces the cognitive load of the students. The formative evaluations were based on the requirements. Hence, from the formative evaluations we can not conclude whether the learning material really is activating and motivating. Several experts and students took a critical look at the learning material and corrections were implemented after each evaluation step. Therefore we are confident that most requirements that were tested seem to be met. The exercises are now ready for case studies.

\section{DESCRIPTION OF THE DIGITAL EXERCISES}

This section describes the main features of the digital exercises. The section is structured on the basis of a selection of the design guidelines.

\section{g1: prior knowledge should be the entry point}

The way prior knowledge is used as an entry point is threefold:

- level 1 exercises: exercises that are designed to brush up prior knowledge;

- level 2 exercises: exercises that are designed to relate new knowledge to prior knowledge;

- level 3 exercises: exercises that ask students to reason, to combine prior knowledge and new knowledge, and to draw conclusions.

Level 1 exercises brush up prior knowledge, which is important knowledge for understanding various concepts in food chemistry. An example is an exercise about the structural forces in proteins. It is assumed that students are already familiar with these structural forces, so this exercise is designed to make students aware that this knowledge is also important for food chemistry.

The level 2 exercises add new knowledge to assumed prior knowledge: assumed prior knowledge is rehearsed and new knowledge is introduced and relations to food chemistry situations are shown. The aim of this kind of exercises is supporting the acquisition and elaboration of know-what knowledge. An example is an exercise in which the structural properties of monosaccharides that are of importance for food chemistry (glucose, fructose, galactose: structures that are assumed to be prior knowledge) are elaborated and are related with properties like taste and source.

Level 3 exercises also combine assumed prior knowledge and new knowledge. These exercises differ from type 2 exercises in the sense of reasoning: the aim of these exercises is supporting the acquisition and elaboration of know-how knowledge.

\section{g8: use each time a different type of exercise}

Several types of exercises were used, which means that there are several possible assignments a student can be asked to do. The different types that are used to make an 
TABLE 3: Different types of digital exercises that were used.

\begin{tabular}{|l|l|l|}
\hline Type of exercise & purpose of exercise & Degrees of freedom depends on: \\
\hline $\begin{array}{l}\text { Multiple choice: } \\
\text { Choose one correct answer from } \\
\text { several options }\end{array}$ & Focus on definitional knowledge. & - the number of options \\
\hline $\begin{array}{l}\text { Multiple answer: } \\
\text { Choose more than one correct answer } \\
\text { from several options }\end{array}$ & $\begin{array}{l}\text { Focus on the relationship of items to } \\
\text { one specified category. }\end{array}$ & $\begin{array}{l}\text { - the number of options } \\
\text { - the number of correct answers } \\
\text { - whether the student knows how } \\
\text { many correct answers there are }\end{array}$ \\
\hline $\begin{array}{l}\text { Categorising: } \\
\text { Group items into several categories }\end{array}$ & $\begin{array}{l}\text { Focus on categories that exist in food } \\
\text { chemistry, e.g. the 20 amino acids } \\
\text { that can be grouped in several } \\
\text { categories. }\end{array}$ & $\begin{array}{l}\text { - number of categories } \\
- \text { whether categories can hold a (for } \\
\text { the student known) maximal number } \\
\text { of items }\end{array}$ \\
\hline $\begin{array}{l}\text { Matching: } \\
\text { Match items that belong together }\end{array}$ & $\begin{array}{l}\text { Focus on the relation between items, } \\
\text { e.g. relation between a structural and } \\
\text { a physical property. }\end{array}$ & $\begin{array}{l}\text { - presence of categories } \\
- \text { number of categories } \\
\text { - number of items (per category) } \\
\text {-number of fake items }\end{array}$ \\
\hline $\begin{array}{l}\text { Ranking: } \\
\text { Rank items into a correct order }\end{array}$ & $\begin{array}{l}\text { Focus on processes or specific } \\
\text { sequences in reactions. }\end{array}$ & $\begin{array}{l}\text { - the number of items } \\
\text { - the number of fake items }\end{array}$ \\
\hline $\begin{array}{l}\text { Point out: } \\
\text { Point to a certain area in a visual (no } \\
\text { specific areas are highlighted for } \\
\text { pointing, since then this would be a } \\
\text { multiple choice question) }\end{array}$ & $\begin{array}{l}\text { Focus on the spatial position of a } \\
\text { certain item (hot spot), e.g. the free } \\
\text { amino group in a protein. }\end{array}$ & $\begin{array}{l}\text { each position in a visual can be } \\
\text { pointed out by a student }\end{array}$ \\
\hline $\begin{array}{l}\text { Fill in the blank: } \\
\text { Fill in an answer, which can be a } \\
\text { calculated number (no specific } \\
\text { possible answers that can be filled in } \\
\text { are given) }\end{array}$ & Focus on calculation. & any number can be filled in \\
\hline
\end{tabular}

interactive exercise are: multiple choice, multiple answer, categorising, matching, ranking, point out and fill in the blank. Cucchiarelli, Panti, and Valenti (2000) gave a somewhat comparable list of question types.

In Table 3 each type of exercise and the reason why the designer could choose this type are given. The table also shows that the degree of freedom (number of choices the student has in performing the exercise) depends on the type and the way this type is used.

Each type of exercise was used for level 1, level 2 and level 3 exercises. By choosing a certain type the level of difficulty of the exercise was manipulated, for example by increasing the number of degrees of freedom. Table 4 gives an example for each type of exercise.

The digital exercises use basically four different possible actions to interact: fill in a number or letter(s), drag an object, click on an object, and mouse-over functions. These four actions give the designer plenty possibilities to make activating learning material. For each type of exercise all four actions were used.

\section{g2: one new concept at the time}

The exercises differ in many ways. Each exercise is related to a specific learning goal, dealing with a certain topic. Each exercise is independent from another concerning the topic of the exercise, but the prior knowledge is increasing in the course of the sequence. There are several topics for the exercises as shown in Table 5 and many exercises contain combinations of topics. Each topic can be used for level 1, level 2 or level 3 exercises. Each topic may 
TABLE 4: Example for each type of exercise.

\begin{tabular}{|l|l|}
\hline Technique & Example \\
\hline Multiple choice & $\begin{array}{l}\text { The exercise: Where are the side-groups of the amino acids in an } \alpha \text {-helix situated? } \\
\text { The options: a. In the inside of the helix, b. Outside of the helix, c. Both inside and outside of } \\
\text { the helix. (just one answer is right) }\end{array}$ \\
\hline Multiple answer & $\begin{array}{l}\text { The exercise: Point out which of these items are related to starch. } \\
\text { The options: } \alpha \text {-glucose, } \beta \text {-glucose, reducing sugar, non-reducing sugar, milk, potatoes, rice, } \\
\text { bananas, meat, etc. (more than one answer need to be pointed) } \\
\text { (see also figure 6.1) }\end{array}$ \\
\hline Categorising & $\begin{array}{l}\text { The exercise: Categorise each of the } 20 \text { amino acids into one of the six categories according } \\
\text { to their side-group. } \\
\text { The options: For each amino acid there are } 6 \text { options. Students see that the categories have } \\
\text { fixed numbers of items that it can hold. }\end{array}$ \\
\hline Matching & $\begin{array}{l}\text { The exercise: Select for each graph (Click) the belonging reaction formula and the result from } \\
\text { this reaction. } \\
\text { Rhe options: there are three graphs, three formulas and three results that need to be matched } \\
\text { (see also figures 2.3, 3.1, 4.1, and 5.1) }\end{array}$ \\
\hline Point out & $\begin{array}{l}\text { The exercise: Put the various stages of the formation of a gel in the right order. } \\
\text { The options: there are 5 stages the first is "moving macro-molecules" and the last is "network } \\
\text { can hold water" }\end{array}$ \\
\hline Fill in the blank & $\begin{array}{l}\text { The exercise: Point to the structural group in the protein molecule that reacts with sugar in the } \\
\text { Maillard reaction. } \\
\text { The options: A molecular structure is shown and the student can click anywhere in this } \\
\text { structure. Only one spot corresponds with the right answer. }\end{array}$ \\
$\begin{array}{l}\text { The exercise: Calculate the sugar concentration of a solution and fill this number in. The } \\
\text { needed numbers and formula are given. } \\
\text { The options: A blank is given where the student can fill in any number. }\end{array}$ \\
\hline
\end{tabular}

TABLE 5: Categorising the topics of the digital exercises.

Main topics of the digital exercises:

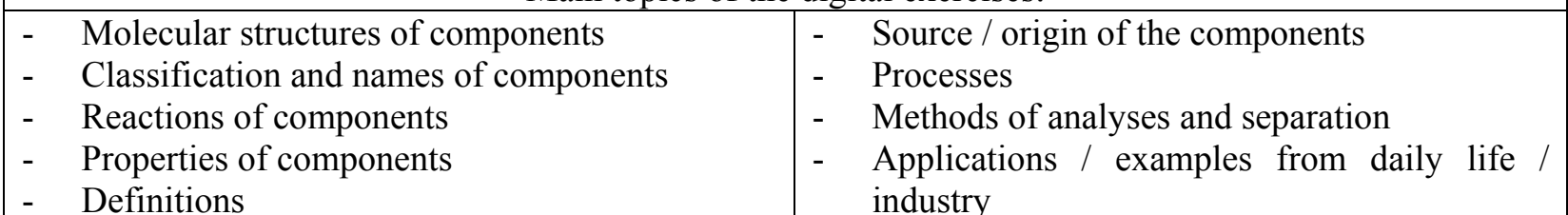

consist of many concepts, but during the exercise maximal one concept of the topic (-s) is assumed to be new to the student.

\section{g3: JIT presentation}

JIT presentation of information can refer to the presentation of information at the beginning of an exercise, during an exercise or after completion of an exercise. Table 6 shows which type of information should be given at which stage and the reason for it.

Information before, during or after an exercise can be given in different forms, for example a table, a scheme, a static visual, a text or an animation. Information that is given during an exercise is accessible in two ways: 1 . the information must be called up consciously (for example by clicking on a button), and 2. the information is feedback (hint or reaction on answer), which is given after submitting an answer. 
TABLE 6: When information can be given and possible reasons for this moment.

\begin{tabular}{|c|c|}
\hline When & Reason(-s) \\
\hline $\begin{array}{l}\text { Beginning } \\
\text { of the } \\
\text { exercise }\end{array}$ & $\begin{array}{l}\text { 1. Activation of prior knowledge. } \\
\text { 2. This information is necessary to start the exercise. By providing this information in the } \\
\text { beginning students do not have to seek for it, which saves time and reduces cognitive } \\
\text { load. } \\
\text { 3. The exercise elaborates on the information that students read or saw just a moment ago, } \\
\text { which is a form of rehearsal and application of knowledge. }\end{array}$ \\
\hline $\begin{array}{l}\text { During the } \\
\text { exercise }\end{array}$ & $\begin{array}{l}\text { 4. During the exercise students need certain facts that they are not supposed to know by } \\
\text { heart, but that are necessary to complete this exercise (e.g. the definitions of penta, } \\
\text { nona and deca). } \\
\text { 5. Students need information to be able to complete the exercise (e.g. they have no clue } \\
\text { what to do or the number of possibilities is too large). }\end{array}$ \\
\hline $\begin{array}{l}\text { After the } \\
\text { exercise }\end{array}$ & $\begin{array}{l}\text { 6. During the exercise students use their prior knowledge, common sense and presented } \\
\text { information. After completion, students could need extra explanation, additional } \\
\text { information or a summary, to reflect on the just acquired knowledge. }\end{array}$ \\
\hline
\end{tabular}

\section{g7: gradually build up the difficulty}

The Food Chemistry course gives the students an introduction to the structures, important properties and important chemical reactions of the most important components in food systems: proteins, carbohydrates, lipids, phenolic components and enzymes. For each of the five components exercises are designed which are grouped in sequences of each maximal 10 exercises. In total 14 sequences are developed containing in total 107 exercises.

According to Sweller (Sweller 1994) "difficulty of learning is closely related to the number of items that need to be learned and the level of association between these items, which is related to cognitive load". The difficulty of a task is also closely related to whether schemata already exist in memory to solve the task. If schemata do not exist, a task can be very difficult although cognitive load can be low. Hence, the topic, the number of concepts, the type of exercise (especially the number of degrees of freedom) and the prior knowledge of the student determines the degree of difficulty of the learning task. These parameters have been used to control the degree of difficulty of the exercises.

Both from sequence to sequence as well as within each sequence the difficulty of the exercises is gradually increasing: the first sequence is in general easier than the second and the third and the first question of a sequence is in general easier than the last question. For example the amino acid sequence contains exercises about what amino acids are and in what kind of reactions they are involved. The sequence on properties of peptides assumes that the students know about amino-acids, which means a higher assumed prior knowledge than the sequence on amino acids, and starts with exercises about peptide bonds and ends with exercises about specific known peptides and some functions. The last sequence of this subject, properties of proteins, assume knowledge about both amino acids and peptide bonds, which means that the assumed prior knowledge is even higher than the sequence on peptides. Students are therefore invited to start with the first sequence of a subject, but it is not a necessity. The sequences have the purpose to give guidance: by gradually building up the degree of difficulty of the concepts in the exercises students are guided in their search to understand food chemistry concepts. Each task within an exercise can be kept simple, while after a sequence of exercises many complex concepts are dealt with. 


\section{g4: visualise and integrate words and visuals}

Much can be presented visually. Examples are molecular structures, schemas, processes, drawings, tables, photos and animations. The use of colours, buttons, mouse-over functions and screen lay-out are important tools for visual presentation of information. Several examples of visualisation will follow (Figures 2, 3, 4, 5 and 6).

\section{g22: strive for consistency, and g23: assist in navigation}

Each sequence and each exercise has the same lay-out. Navigational information is consistently presented in the same area of the screen and colours and buttons are consistently used to assist the student in navigation. For instance the overall colour of the first sequence is different from the second and third sequence, so the student can distinguish the sequences.

Figure 2.1 shows the start of a sequence. The name of the sequence "applications of enzymes" shows the student the subject of exercises of this sequence. When clicking the start-button in Figure 2.1 the student starts this sequence of exercises and arrives at the first exercise, shown in Figure 2.2. The navigation-buttons top left show the student that there are in total five exercises. The number of the exercise the student is working on is bold and the student can click on each of the numbers to go to any other exercise or can click on "score" to go to the total score list (Figure 2.6). In this way the student is free to navigate to each exercise. Top right the student can see his or her score for that particular exercise. For each exercise the student can earn 10 points. Centred at the top the student can read what has to be done in this exercise. In this particular example the student first has to move his mouse over an amylopectin molecule, to find out which enzymes degrade which parts of the amylopectin molecule (Figure 2.2).

By clicking on the assignment-button the student arrives at the real exercise (Figure 2.3). The assignment-button is always used when the exercise starts with some information before going to the real exercise. In the exercise in Figure 2.3 the student has to indicate which graph corresponds with which enzyme preparation. In this example the student already filled in the answers and is about to click OK. In all exercises, for the students the function of the OK-button is checking the answer. After clicking OK, the computer indicates whether the particular answers are right or wrong (Figure 2.4). By clicking on the arrow the student arrives at the end of the exercise, where some explanation is given (Figure 2.5). An arrowbutton is always used to go to a next stage within the same exercise. This is very often an explanation. Bottom right there is a link to the next exercise by means of a next-button. Clicking on the next-button is always bringing the student to the next exercises. At the end, the score of each exercise is shown in a score overview, as shown in Figure 2.6.

\section{9: provide examples from the food industry, from the lab and from daily life}

By providing examples from food industry or daily life students see the use of the knowledge they have to learn. Examples can come from a butcher as in the example in Figure 3.1 , but it can also come from for example a lemonade factory (brown colouring in orange juice), a bakery (S-S-bridge forming in bread), or the taste of French cheese (lipid oxidation products). 


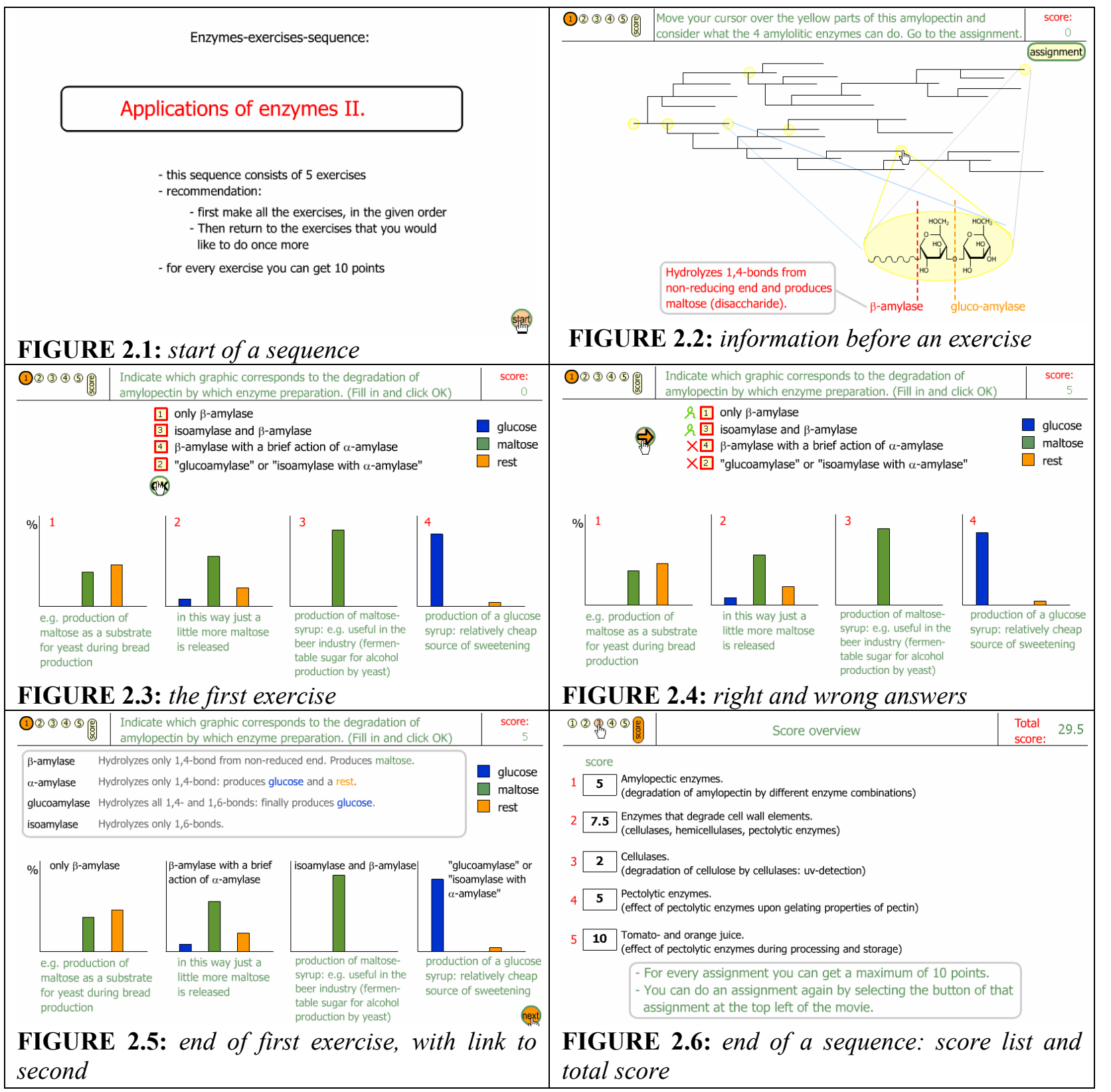

FIGURE 2: An example of various stages within a sequence of exercises.

The exercise in Figure 3.1 is built around the situation of a butcher who wants to develop three meat sauces. The sauces differ in $\mathrm{pH}$ and salt-concentration. Students have to tell what the meat structure will look like with each of the sauces $(\mathrm{pH}$ and salt-concentration both influence the water binding capacity of fibrillary proteins). In this exercise students combine three sauces and three representations of meat structure, by matching the number of the sauce to each representation. After correctly answering the question, the student arrives in Figure 3.2. Some information is given during or before the exercise (e.g. the iso-electric point of actomyosine, see Figure 3.1) and at the end the effect of $\mathrm{pH}$ and salt is explained (see Figure 3.2). In this example a clear relation between food chemistry (water binding of proteins affected by $\mathrm{pH}$ and salt) and the food industry (meat industry) is shown. 


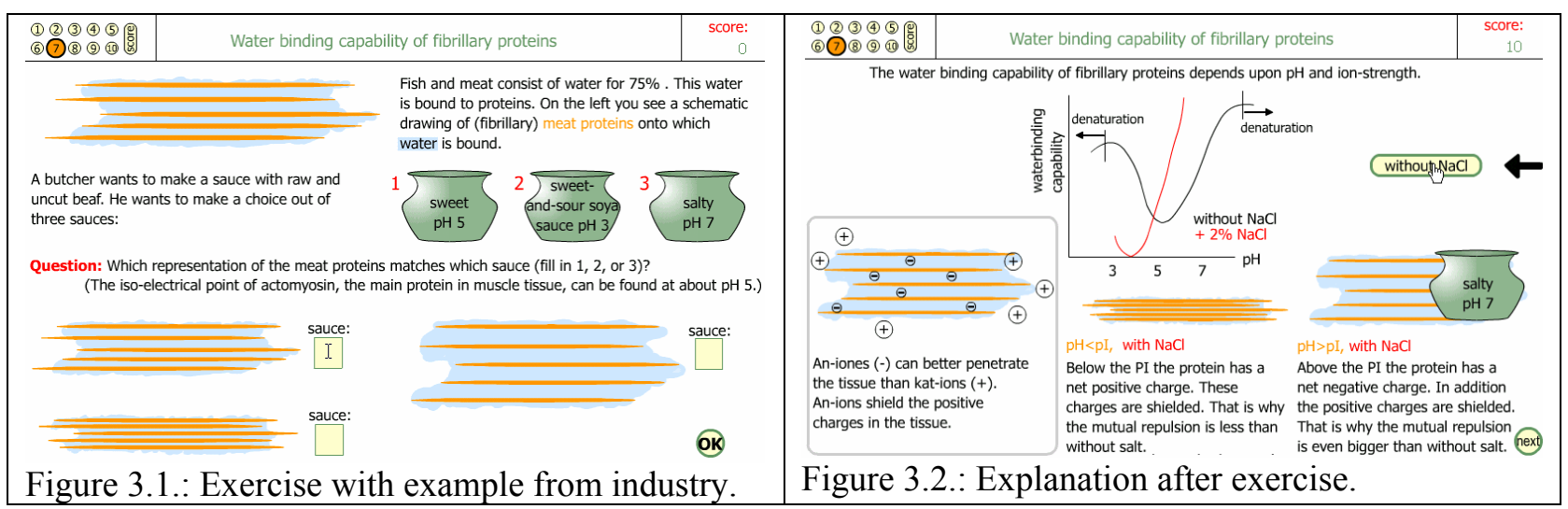

FIGURE 3: An example of an exercise that provides an example from the food industry.

\section{g10: make clear what are important reactions and concepts}

In short, in Food Chemistry there are a number of important reactions, for example reactions induced by polyphenol oxidase (a.o. enzymatic browning), lipid oxidation and Maillard reactions. These reactions are the main reactions that influence quality properties of food like taste, colour and shelf-life. The rate or existence of these reactions depends on many kinds of environmental properties like $\mathrm{pH}$ and temperature. To show how important these reactions are several exercises were designed that handle these reactions.

In Figure 4.1 an exercise is shown that is designed to show the effect of the enzyme polyphenoloxidase and the three most important reactions that are induced after oxidation by polyphenoloxidase and their effect. When clicking on hint, the student can get information about each of the reactions related to tea (see Figure 4.2). Students are supposed to complete the scheme with the three reactions by dragging the molecules from the right to the appropriate spot on the left side. At this very moment in Figure 4.1 the user is dragging a quinone to, if the user knows the right answer, the top centre spot, from where three arrows go to three different reactions.

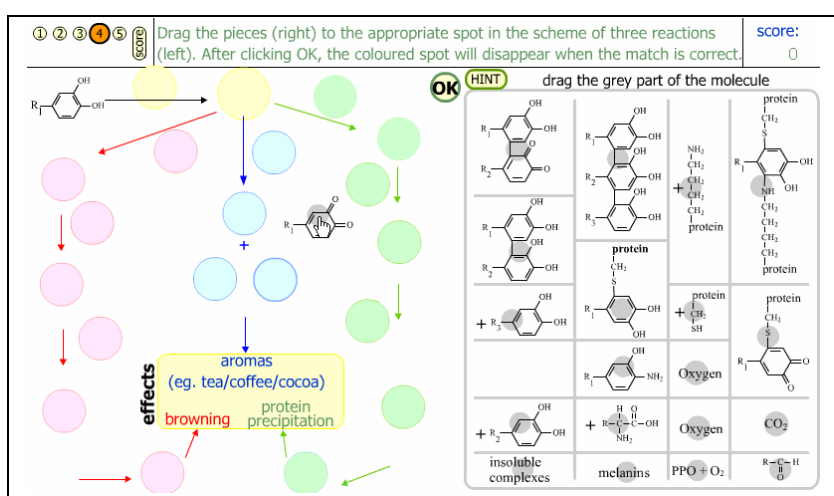

FIGURE 4.1.: Exercise that involves working with different reactions.

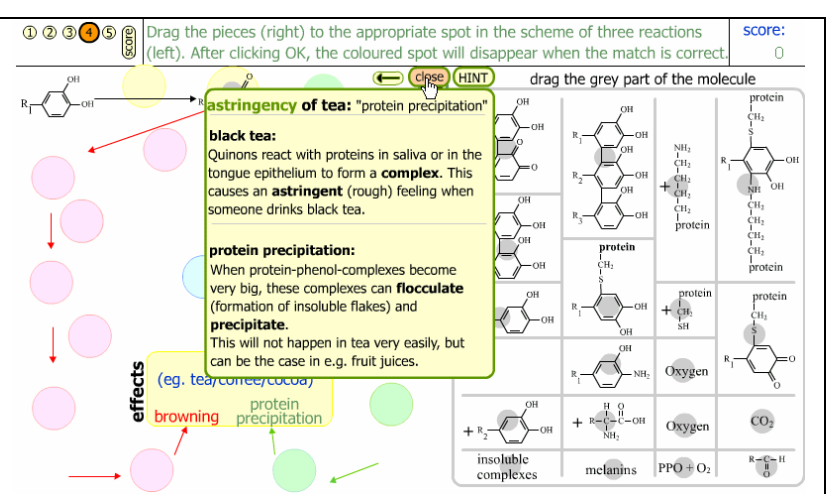

FIGURE 4.2.: Importance of the reaction become especially clear in the hints.

FIGURE 4: An example of an exercise that shows the importance of reactions induced by the enzyme polyphenoloxidase. 


\section{g12: include a motivational element}

By using a game or anything else that increases extrinsic motivation when instrinsic motivation is likely to be low, a motivational element can be included in exercises, for example a mahjong game (see Diederen 2002) or a jig-saw puzzle.

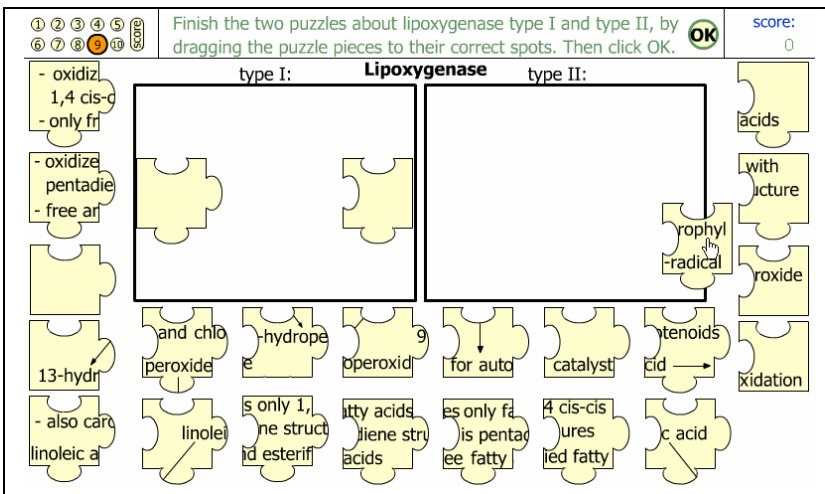

FIGURE 5.1.: Exercise that is a kind of game: a jig-saw puzzle.

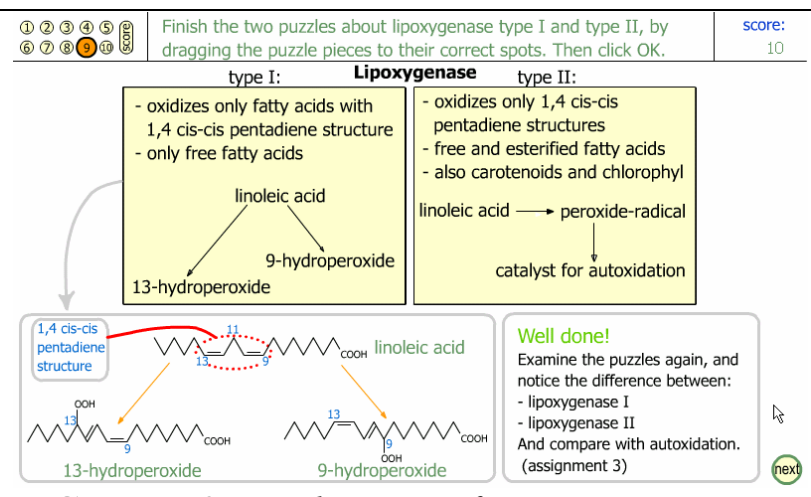

FIGURE 5.2.: Explanation after exercise.

FIGURE 5: An example of an exercise that includes a motivational element by means of a jig-saw puzzle.

In the exercise in Figure 5.1 the student has to complete two jig-saw puzzles by dragging the puzzle pieces into the two squares. There are two possibilities to complete the two puzzles. The puzzle pieces fit in both puzzles so you could put all the pieces of the left puzzle on the right and the pieces of the right in the left and still have two complete puzzles. But, only one possibility is right: the pieces that belong to lipoxygenase type I should be dragged to the left puzzle and the pieces of lipoxygenase type II to the right. These two types both oxidise a specific structure in a lipid, but one type can react with only one kind of substrate and the other type with several. The screenshot Figure 5.2 shows the information that is given after completion of the two puzzles: there is some additional information and explanation what happens with linoleic acid when it is oxidised by lipoxygenase.

\section{g17: provide hints and feedback}

The digital exercises contain feedback and hints. The easiest form of feedback is an indication whether an answer is right or wrong. Apart from this, feedback could also give a reason why something is wrong. Hints are most of the time incorporated to guide the thinking process. Without these hints it could be very difficult for the student to decide what to do after a wrong answer. To help a little, the exercise gives the student a hint that is supposed to guide the student along a suitable line of reasoning or to give the student an indication that certain prior knowledge may not be correct.

An example of both feedback and hints is visualised in the screenshot from an exercise on galacto-oligosaccharides (Figure 6.1). The student has to select those words that do apply to this group of saccharides. When clicking OK the student gets two pieces of information: 1. the number of mistakes (in this example 6) (which is a form of feedback) and 2. a hint. The hint is generated according to the answer of the student. So each time the student clicks OK a hint appears that is related to a word that still is not selected or should be deselected. When the number of mistakes is reduced to zero, the student reaches the end of 


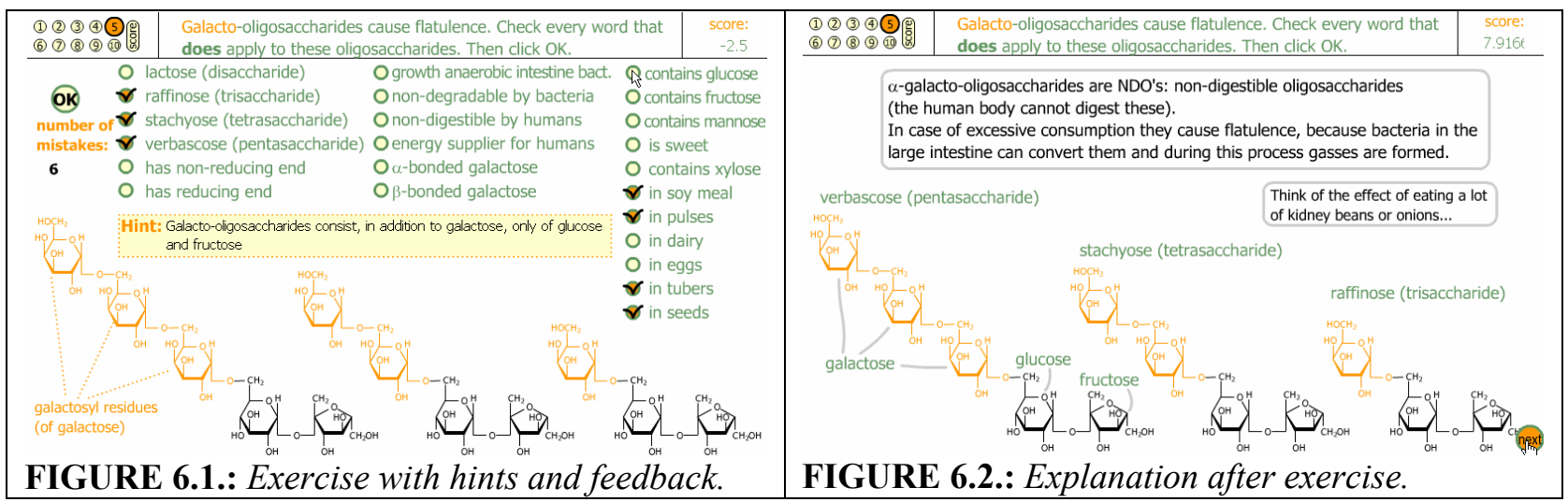

FIGURE 6: An example of an exercise that provides feedback and hints.

the exercise, where some additional information is given (Figure 6.2) (an example of "information at the end of an exercise").

\section{g15: force students to actions}

To catch or direct the attention of the student the exercises should contain elements that force students to an action. Without this action nothing happens. This was done in many different ways in the digital exercises, for example:

- Mouse-over function in where a student only gets the information after moving the mouse over a specific area

- Buttons that students have to click on to get information or to start a movie (animation)

An example of an exercise where students are forced to an action is shown in Figure 7.1. In this exercise students first have to take a look at a molecule. At first instance, there is not much information on the screen. Students will only get information by moving the mouse over the yellow parts of the molecule, which is the case in Figure 7.2. Students are forced to an action: without moving the mouse students will not have the necessary information. After reading all information students can go to the assignment (by clicking on button saying "assignment" on top in figure 7.1). In this assignment students need the information that they can read behind each yellow part of the structure. This exercise is a clear example of "information before an exercise".

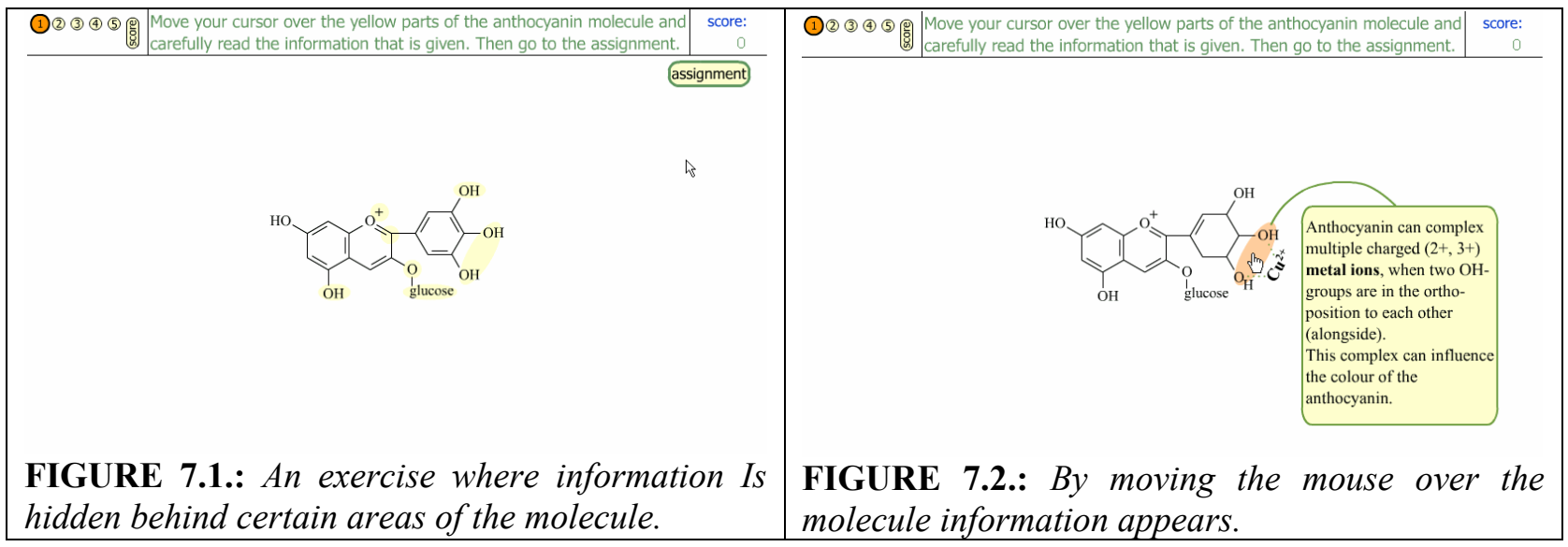

FIGURE 7: An example of an exercise that forces students to actions. 


\section{CONCLUSIONS}

In total 108 digital exercises have been designed, developed, evaluated and improved. The design process was guided by a set of design guidelines and design requirements. Sometimes guidelines and requirements overlap, but always guidelines and requirements are each others complement. During the design process the guidelines turned out to be very useful as a means to assure that the exercises are in line with the requirements. The implementation of the design guidelines resulted in a lot of practical experience on how to design activating exercises. This experience has been described in detail in the last section of this paper.

The formative evaluations were very useful to make sure that the exercises are usable and do not contain serious shortcomings in the form of bad user interface design, errors in content or didactical mistakes. Because of the formative evaluations, errors could be eliminated to make the exercises ready for real-life implementation in the course.

In short, this paper shows how guidelines are used to build a bridge between the theories on learning and instruction and the practical challenge of designing digital learning material.

\section{FINAL REMARKS}

All exercises are developed with Flash5 ${ }^{\circledR}$ (Macromedia) and are provided through the world wide web with the help of Blackboard $\AA$, a web based learning management system. Some examples of the exercises are available on the website www.fbt.eitn.wau.nl/foodchemistry.

The exercises are used and evaluated in a case-study within the regular stetting at Wageningen University. Students worked individually behind a computer during a few computer classes. Besides these classes, students could access the material anytime. Results from this study are promising (e.g. students' rate on the statement "digital exercises are valuable" is 4.6 on a 5-point scale) and are showing a successful implementation of the product. A paper about this case-study is in progress. At this moment, in addition to Wageningen University, the exercises are in use at Cornell University.

ACKNOWLEDGEMENTS: The students and experts are acknowledged for their formative evaluation efforts.

CORRESPONDENCE: Alphons G.J. VORAGEN, Wageningen University, Department of Agrotechnology and Food Sciences, Laboratory of Food Chemistry, P.O. Box 8129, 6700 EV Wageningen,The Netherlands; e-mail:Fons.Voragen@wur.nl

\section{REFERENCES}

Anderson, J. R. (1995). Learning and memory. An integrated approach. John Wiley \& Sons, Inc.

Ausubel, D. P. (1968). Educational psychology: A cognitive view. London: Holt Rinehart and Winston.

Baddeley, A. (2000). The episodic buffer: A new component of working memory? Trends in cognitive Sciences, 4, 417-423.

Baddeley, A. D. (1992). Working memory. Science, 255, 556-559.

Bannert, M. (2002). Managing cognitive load - recent trends in cognitive load theory. Learning and Instruction, 12, 139-146. 
Biemans, H. J. A. (1997). Fostering activation of prior knowlegde and conceptual change. Onderwijskunde (Department of Education). Nijmegen, the Netherlands: Katholieke Universiteit Nijmegen.

Cucchiarelli, A., Panti, M., Valenti, S. (2000). Web-based assessment in student learning. In Webbased learning and teaching technologies: Opportunities and challenges, A. Aggarwal (ed.), pp. 175-197. Hersheys (USA), London (UK): Idea Group Publishing.

Denis, M. (1994). Image and cognition. Paris: Presses Universitaires de France.

Diederen, J., Gruppen, H., Voragen, A.G.J., Hartog, R., Mulder, M., Biemans, H. (2002). Design guidelines for digital learning material for food chemistry education. Ed-Media 2002 World Conference on Educational Multimedia, Hypermedia \& Telecommunications. Denver.

Hull, C. (1940). Mathematico-deductive theory of rote learning. New Haven, NJ: Yale Univeristy Press.

Johnstone, A. H. (2001). Can problem solving be taught? University Chemistry Education, 5, 69-73.

Keller, J. M. (1983). Development and use of the ARCS model of motivational design. Report No. IR 014 039. ERIC Document Reproduction Service No. ED 313 001).

Kester, L., Kirschner, P.A., van Merriënboer, J.J.G., Baumer, A. (2001). Just-in-time information presentation and the acquistion of comples cognitive skills. Computers in Human Behaviour, $17,373-391$.

Keyser, M. W. (2000). Active learning and cooperative learning: understanding the difference and using both styles effectively. Research Strategies, 17, 35-44.

Kirschner, P. A. (2002). Cognitive load theory: Implications of cognitive load theory on the design of learning. Learning and Instruction, 12, 1-10.

Marcus, A. (1997). Graphical user interfaces. In Handbook of human-computer interaction, M. G. Helander, Landauer, T.K., Prabhu, P.V. (eds.), pp. 423-440. Amsterdam: Elsevier Science B.V.

Mayer, R. E. (2002/3). The promise of multimedia learning: using the same instructional design methods across different media. Learning and Instruction, $x x(x x)$, $\mathrm{xx}$.

Mayer, R. E., Moreno, R. (2003). Nine ways to reduce cognitive load in multimedia learning. Educational Psychologist, 38, 43-52.

Merriënboer, J. J. G. v. (1997). Training complex cognitive skills. Englewood Cliffs, New Jersey: Educational Technology Publications.

Owen, E., Sweller, J. (1989). Should problem solving be used as a learning device in mathematics? Journal for Research in Mathematics Education, 20, 322-328.

Sweller, J. (1988). Cognitive load during problem solving: Effects on learning. Cognitive Science, 12, 257-285.

Sweller, J. (1994). Cognitive load theory, learning difficulty, and instructional design. Learning and Instruction, 4, 295-312.

Sweller, J., Merrienboer, J.J.G., Paas, F.G.W.C (1998). Cognitive architecture and instructional design. Educational Psychology Review, 10, 251-296.

Weston, C., Gandell, T., McAlpine, L., Finkelstein, A. (1999). Designing instruction for the context of online learning. The Internet and Higher Education, 2, 35-44. 